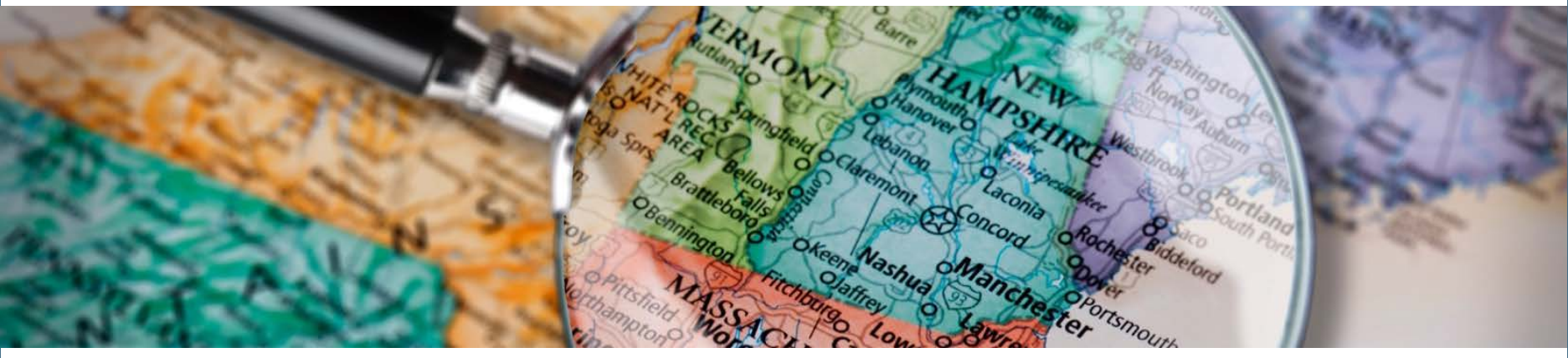

Regional Brief | 2019-01 | April 9, 2019

\title{
Declining Access to Health Care in Northern New England
}

\author{
Riley Sullivan
}

\section{Summary}

Access to health care is a major concern across the northern New England states-Maine, New Hampshire, and Vermont-where rising operating costs and population loss threaten the stability of hospitals and other medical facilities that serve their surrounding rural communities. New analysis of financial data shows that many rural hospitals are operating at losses that are predictive of financial distress or even closure. Consequently, the communities served by these hospitals may be at risk of losing the benefits they provide to public health and the local economy.

Addressing the financial health of medical facilities in rural areas poses a complicated challenge for policymakers working to sustain or revitalize the economies of these communities.

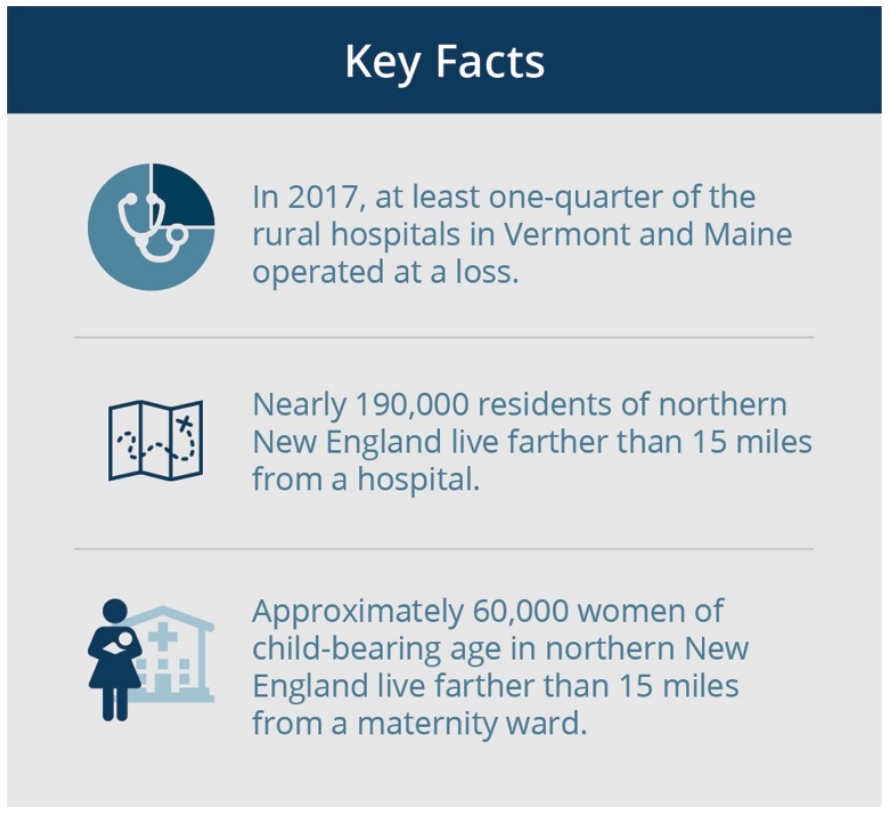
This report reviews recent data on hospital profitability and explores health care from a geographic perspective, looking at how a community's distance from a hospital or other medical facility affects the health and well-being of residents and the local economy. 


\section{Risk of Hospital Closures in Northern New England}

In the United States since 2010, about 90 rural hospitals have closed, most of them in the

Southeast but in other regions as well. ${ }^{1}$ Hospitals in rural areas are particularly vulnerable to the factors that drive a closure, and as a consequence, many counties across the country now lack even a single hospital. The National Rural Health Association identifies more than 600 additional hospitals with characteristics similar to those of hospitals that have closed, suggesting that they may be at risk of shutting down. ${ }^{2}$

Other research identifies hospitals in northern New England as being at risk of going into bankruptcy and closing. ${ }^{3}$ The North Carolina Rural Health Research Program (NCRHRP) notes that the finances of rural hospitals in Maine have deteriorated since 2011, with seven of the state's 16 Critical Access Hospitals (CAHs) showing negative financial margins in $2015 .{ }^{4} \mathrm{CAH}$ designation is granted to small hospitals that serve remote populations, and it allows providers to bill Medicare for the cost of services rather than a set rate. ${ }^{5}$ A 2018 report by the NCRHRP using 2016 data points to non-CAH hospitals in the Northeast as one of the least profitable groups of hospitals, along with CAHs in the South. ${ }^{6}$

\section{Rural Hospitals' Operating Margins}

Rural hospitals run tight, in some cases even negative, margins. Table 1 shows the NCRHRP findings for northern New England, presenting data on the profitability of hospitals by type (Critical Access Hospitals, other rural hospitals, urban hospitals) for each of the three states in 2017. The data make clear the tenuous financial situation of rural hospitals across the region, particularly in Vermont, where the median $\mathrm{CAH}$ operated at a loss. ${ }^{7}$ At least 25 percent of the other rural hospitals in Vermont also operated in the red that year. In Maine, one-quarter of the CAHs and one-quarter of the other rural hospitals operated at a loss in $2017 .{ }^{8}$

In recent years, news outlets in Maine, New Hampshire, and Vermont have featured stories about rural-hospital instability and the potential for closures in their states. ${ }^{9}$ In January 2019, one of the hospitals included in that news coverage, Penobscot Valley Hospital in Lincoln, Maine, filed for Chapter 11 bankruptcy protection. As reasons for the filing, the hospital cited cuts to reimbursement rates from the state's Medicaid program as well as a steep decline in in-patient admissions in recent years amid an economic downturn in the area. ${ }^{10}$

Declining admissions can be driven, in part, by population loss, which most of rural northern New England is experiencing. According to census estimates, between the years 2010 and 2017, 10 of Maine's 16 counties, 9 of Vermont's 14, and 3 of New Hampshire's 10 lost population. Such declines also increase the difficulty of finding skilled health-care professionals to staff medical facilities. 


\section{Table 1: Hospital Operating Profit Margins}

Northern New England States, 2017

\begin{tabular}{|c|c|c|c|c|c|}
\hline State & Type & \# & 25th Percentile & Median & 75th Percentile \\
\hline Maine & Critical Access Hospitals & 16 & $-0.67 \%$ & $0.98 \%$ & $5.11 \%$ \\
\hline Maine & Other Rural Hospitals & 9 & $-1.18 \%$ & $0.90 \%$ & $2.26 \%$ \\
\hline Maine & Urban Hospitals & 8 & $-1.21 \%$ & $1.36 \%$ & $2.82 \%$ \\
\hline New Hampshire & Critical Access Hospitals & 12 & $1.03 \%$ & $3.36 \%$ & $6.76 \%$ \\
\hline New Hampshire & Other Rural Hospitals & 4 & $0.80 \%$ & $3.64 \%$ & $10.83 \%$ \\
\hline New Hampshire & Urban Hospitals & 8 & $2.96 \%$ & $12.04 \%$ & $24.85 \%$ \\
\hline Vermont & Critical Access Hospitals & 8 & $-4.88 \%$ & $-1.49 \%$ & $3.50 \%$ \\
\hline Vermont & Other Rural Hospitals & 5 & $-0.17 \%$ & $1.42 \%$ & $4.45 \%$ \\
\hline Vermont & Urban Hospital & 1 & \multicolumn{3}{|c|}{ Suppressed (only one hospital) } \\
\hline
\end{tabular}

Source: Calculations by the North Carolina Rural Health Research Program using 2017 Medicare Cost Reports

\section{Consequences of Closure}

The closure of hospitals and other health-care facilities affects the local economy as well as the health of the local population. Hospitals are economic engines for their communities, and the closure of a facility or service can have an adverse impact on employment. Across the country, 5.9 million people are employed directly by hospitals. In northern New England, employees who fall into the broader category of health-care workers make up about 10 percent of each state's workforce. ${ }^{11}$ Rural hospitals are often one of the largest providers of higher-skill and higher-wage employment in their communities. 
One study on the impact of rural-hospital closures indicates that the shuttering of the sole hospital in a rural community reduces per-capita income by 4 percent and increases the unemployment rate by 1.6 percentage points. Closures in communities with other sources of hospital care have no long-term economic impact, although local income decreases, on average, for two years following the shutdown. ${ }^{12}$

\section{Impact of Distance from a Hospital}

Proximity to hospitals and health-care centers is not merely a matter of convenience for a community's residents; it has implications for their quality of health. Greater distances from a hospital are linked with negative public-health outcomes. Areas that have morelimited access to health care are likely to have higher rates of fatal accidents, fatal heart attacks, and infant mortality. Also, residents of these areas are less likely to access preventative care or maintenance programs for chronic diseases. ${ }^{13}$

In northern New England, many rural communities have limited access to health care because they are far from the nearest medical facilities. This is particularly true for communities in the northernmost parts of the region.

Table 2 shows the number of residents of northern New England by distance from hospitals and Federally Qualified Health Centers (FQHC) in 2019. While FQHCs are not substitutes for hospital care, they do provide primary-care services in underserved areas. ${ }^{14}$ Nationally, these centers serve about 1 in 5 rural residents. ${ }^{15}$ As Table 2 shows, nearly 200,000 residents of northern New England live in census block groups that are farther than 15 miles from a hospital; close to 30,000 of these 200,000 residents live more than 15 miles from the nearest FQHC; more than 10,000 of these residents live farther than 25 miles from a hospital. Closures of hospitals or other health-care facilities would certainly exacerbate the problem.

Due to the dispersion of hospitals across northern New England, a closure of one could result in thousands more residents of the region being great distances from the critical care provided by a hospital. For this reason, many of the hospitals in New England are classified as Critical Access Hospitals. 


\section{Table 2: Population from Nearest Hospitals and Health Centers}

Maine, New Hampshire, and Vermont by

Census Block Group, 2013-2017



Sources: ACS 5-Year Estimates 2013-2017, National Bureau of Economic Research, and Health Resources \& Services Administration

\section{Loss of Maternity Wards}

One way that hospitals in northern New England—and other parts of the country-have responded to financial pressures and demographic changes is to cut services. Thus, even if hospitals remain open, communities' access to maternity wards and facilities that offer other vital services could be threatened. About 9 percent of rural counties in the United States have lost maternity services over the past decade, and about 54 percent of the country's rural counties do not have a hospital with any obstetric services. ${ }^{16}$ Rural communities with more African American and low-income families have suffered more rapid losses of maternity wards than have other rural communities. Perhaps as a consequence, maternal mortality is substantially higher among black women relative to white women and among women living in rural areas versus women living in urban areas. ${ }^{17}$ 
Of the 75 hospitals across Maine, New Hampshire, and Vermont, 22 lacked a maternity ward as of January 2019. Recent maternity-ward closures include those at Alice Peck Day Memorial Hospital in Lebanon, New Hampshire, in 2018; Lakes Region General Hospital in Laconia, New Hampshire, in 2018; Calais Regional Hospital in Calais, Maine, in 2017; and a handful of others. ${ }^{18}$

These closures largely stemmed from decreases in births at these hospitals. For example, just a few years ago, Calais Memorial delivered about 100 babies annually. However, in its final year of operating a maternity ward, the hospital reported just 64 births. ${ }^{19}$ Maternity wards are expensive to operate, and hospitals are unable to scale down these costs when there are fewer births. As a result, hospitals have opted to shutter the units rather than sustain increasing losses.

Across the country each year, about 500,000 women give birth in rural hospitals. ${ }^{20}$ Many of these women have to travel long distances to receive prenatal care, and they need to travel even farther while in labor to get to the hospital to deliver their babies. In northern New England, some 60,000 women aged 18 to 39 live in census block groups that are more than 15 miles from a maternity ward. About 6,000 of these women live farther than 25 miles from a maternity ward. Figure 1 shows the distances between census block groups and hospitals with a maternity ward.

Greater distances to hospitals have been shown to pose health risks to newborns and mothers. Longer travel times can make it more difficult to receive prenatal care, and they are associated with increases in out-of-hospital and preterm births. ${ }^{21}$ 


\section{Figure 1: Distance from Hospitals with Maternity Wards} Northern New England by Census Block Group, 2019
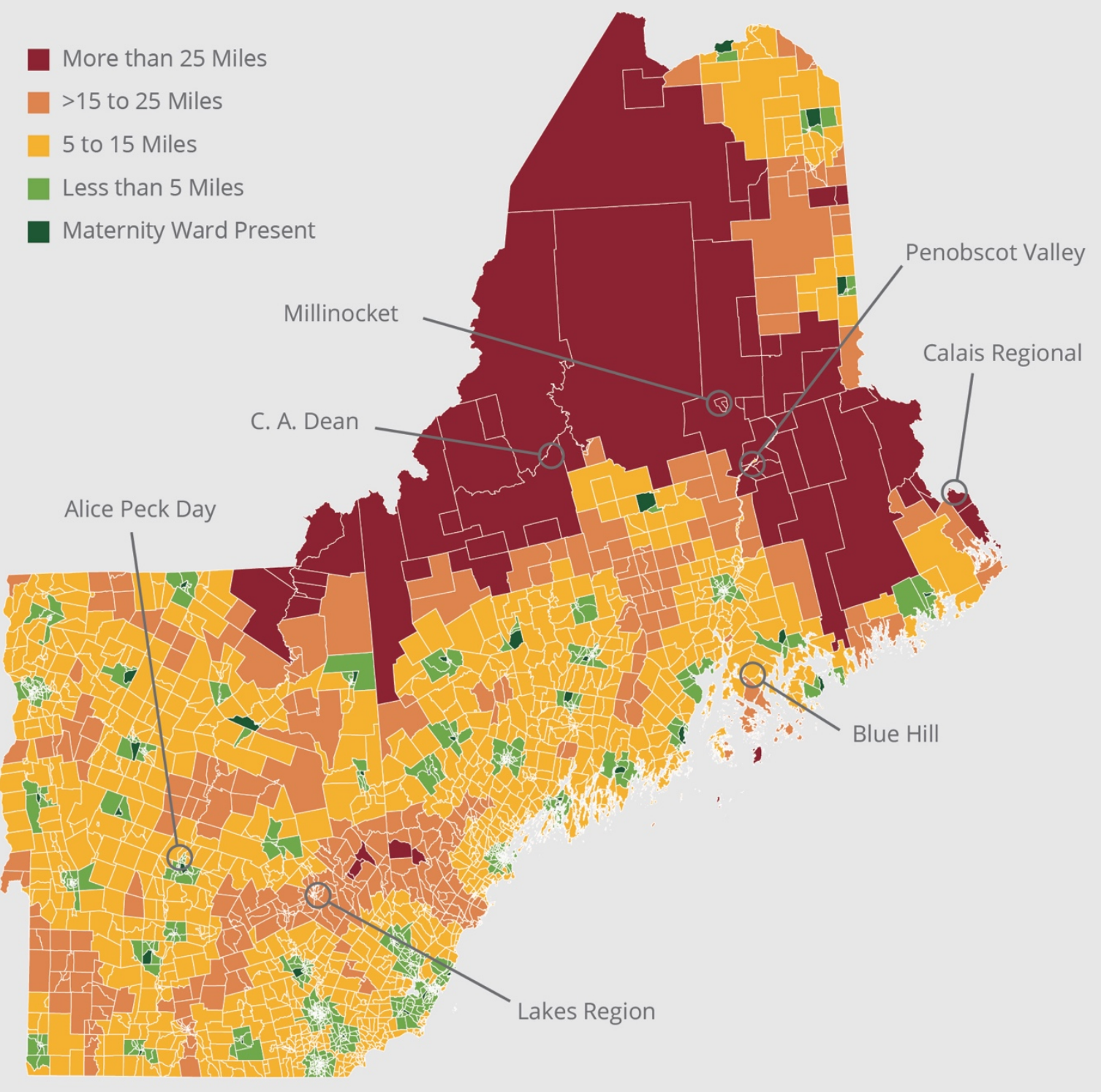

Note: The hospitals identified in the figure closed their maternity wards: Alice Peck Day Memorial Hospital, Lebanon, NH, in 2018; Blue Hill Memorial Hospital, Blue Hill, ME, in 2009; C.A. Dean Hospital, Greenville, ME, in the 1990s; Calais Regional Hospital, Calais, ME, in 2017; Lakes Region General Hospital, Laconia, NH, in 2018; Millinocket Regional Hospital, Millinocket, ME, in 1998; Penobscot Valley Hospital, Lincoln, ME, in 2014. 


\section{Concluding Thoughts}

In recent years, policymakers have given significant attention to the closing of hospitals in rural areas. This attention is warranted given the benefits these facilities provide to their communities. New England has largely been spared the brunt of these closings, but population loss and financial pressures have resulted in decreases in services at some hospitals. Most notable is the elimination of maternity wards. New data on hospital operating margins suggest that the financial pressures on hospitals in rural northern New England are only intensifying.

The public-health and economic consequences of hospital closures, together with the population and demographic changes that are likely key factors driving closures, present a complicated puzzle for policymakers wanting to help sustain rural hospitals or bolster the economies of rural communities.

Despite the complexities, research suggests that some policy interventions have proven helpful in preventing even more rural hospitals from closing. Facilities designated as CAHs-with their higher reimbursement rates-are less likely to close, as are hospitals in states that expanded Medicaid following implementation of the Affordable Care Act. ${ }^{22}$

Other smaller-scale initiatives also hold promise for promoting financial sustainability among rural health-care providers. In 2015, four Critical Access Hospitals in New Hampshire formed an affiliation through which they save administrative costs by consolidating their purchasing, human-resources, marketing, finance, and contracting operations. ${ }^{23}$ In Maine, Penobscot Valley and four of the state's other rural hospitals recently received a newly established grant from the Federal Office of Rural Health Policy to cover the cost of enlisting expert help with stabilizing their business models. ${ }^{24}$

\section{About the Author}

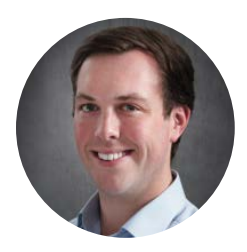

\section{Riley Sullivan}

Riley Sullivan is a senior policy analyst with the New England Public Policy Center. His research interests include income inequality and urban and regional economics. Sullivan is also the editor of New England Economic Indicators, a Federal Reserve Bank of Boston regional data resource. He earned his master's degree in public policy from Georgetown University and his BA in history from Boston College.

Riley.Sullivan@bos.frb.org 
Regional Brief | 2019-01 | Declining Access to Health Care in Northern New England

\section{Data Sources}

Hospital financial data: Analysis provided by the North Carolina Rural Health Research Program using 2017 Medicare Cost Reports.

https://www.shepscenter.unc.edu/programs-projects/rural-health/

Total population data: The data used in this report come from the U.S. Census Bureau's American Community Survey 5-Year Estimates 2013-2017. The data used is by census block groups.

Population of women aged 18 to 39 data: Data by age and sex at the census block group level are from the U.S. Census Bureau 2010 Decennial Census.

Distance data: The measurement of distance is from the center of one census block group to the center of another; the distances are provided by the National Bureau of Economic Research.

Health facility data: Information on hospitals and federally qualified health centers comes from the Health Resources \& Services Administration.

https://data.hrsa.gov/tools/shortage-area/hpsa-find 


\section{Endnotes}

${ }^{1}$ Hospitals in urban and suburban areas also have closed-including three in Maine-but the health and economic consequences, and some of the underlying reasons for these closures, are different from the issues highlighted in this brief. See United States Government Accountability Office, "Rural Hospital Closures: Number and Characteristics of Affected Hospitals and Contributing Factors," August 2018.

2 iVantage Health Analytics. 2016. "Rural Relevance-Vulnerability to Value."

${ }^{3}$ Holmes, George, Brystana Kaufman, and George Pink. 2017. "Predicting Financial Distress and Closure in Rural Hospitals." The Journal of Rural Health 33(3): 239-249.

${ }^{4}$ Coburn, Andrew, and Jay Mullen, "Maine Voices: Rural Hospitals Face Downward Spiral," Portland Press Herald, October 15, 2017.

${ }^{5} \mathrm{~A}$ CAH facility must be located more than a 35-mile drive from any hospital or other $\mathrm{CAH}$, or located more than a 15-mile drive from any hospital or other $\mathrm{CAH}$ in an area with mountainous terrain or only secondary roads, and have no more than 25 inpatient beds (Centers for Medicare and Medicaid Services. "Critical Access Hospitals MLN Booklet." August 2017).

${ }^{6}$ Pink, George H., Kristie Thompson, H. Ann Howard, and Mark Holmes. 2018. "Geographic Variation in the 2016 Profitability of Urban and Rural Hospitals." North Caroline Rural Health Research Program.

${ }^{7}$ There are many ways to define profitability, but the one used here is operating margin, which measures how much profit a company makes on $\$ 1$ of sales, after covering costs associated with administration, materials, wages, and other expenses. It is calculated by dividing a company's operating profit by its net sales.

${ }^{8}$ To maintain hospital confidentiality, only values by quartile are published.

${ }^{9}$ For example, see Savage, Katy, "Springfield Hospital Can't Pay Its Bills. 'It's very unnerving,"' VTDigger, December 11, 2018; Coburn, Andrew, and Jay Mullen, "Maine Voices: Rural Hospitals Face Downward Spiral," Portland Press Herald, October 15, 2017.

${ }^{10}$ Sambines Jr., Nick, "Lincoln Hospital Files for Chapter 11 Bankruptcy Protection," Bangor Daily News, January 29, 2019. The hospital also cited the lack, until recently, of expanded Medicaid coverage in Maine for its decision.

${ }^{11}$ According to the Bureau of Labor Statistics Occupational Employment Statistics, the share of the statewide workforce in the medical field is 10.6 percent in Maine, 8.8 percent in New Hampshire, and 8.9 percent in Vermont.

${ }^{12}$ Holmes, George M., Rebecca T. Slifkin, Randy K. Randolph, and Stephanie Poley. 2006. "The Effect of Rural Hospital Closures on Community Economic Health." Health Services Research 41(2): 467-485.

${ }^{13}$ Buchmueller, Thomas C., Mirielle Jacobson, and Cheryl Wold. 2004. "How Far to the Hospital? The Effect of Hospital Closures on Access to Care." NBER Working Paper No. 10700. Cambridge, MA: National Bureau of Economic Research.

${ }^{14}$ There are just over 200 FQHCs licensed by the U.S. Health Resources and Services Administration in northern New England. An FQHC must meet a stringent set of requirements that includes providing care on a sliding fee scale based on patients' ability to pay and operating under a governing board that includes patients. Additionally, an FQHC must offer services regardless of a person's ability to pay. It must be a nonprofit or public organization, serve a medically underserved area or population, provide comprehensive primary-care services, and have an ongoing quality-assurance program.

${ }^{15}$ Health Resources \& Services Administration. "HRSA Health Center Program Fact Sheet." August 2018.

${ }^{16}$ Hung, Peiyin, Carrie E. Henning-Smith, Michelle M. Casey, and Katy B. Kozhimannil. 2017. "Access to Obstetric Services in Rural Counties Still Declining, with 9 Percent Losing Services, 2004-14." Health Affairs 36(9): 467-485.

${ }^{17}$ Centers for Disease Control and Prevention. "Pregnancy Mortality Surveillance System." 2011-2014 data.

${ }^{18}$ Lawlor, Joe, "As Maternity Services Vanish in Rural Maine, Mothers Expect to Travel Long Distances to Hospitals," Portland Press Herald, September 17, 2017; "The Closing of Maternity Wards-And What to Do About It," New Hampshire Public Radio, November 24, 2018.

${ }^{19}$ Lawlor, Joe, "As Maternity Services Vanish in Rural Maine, Mothers Expect to Travel Long Distances to Hospitals," Portland Press Herald, September 17, 2017.

${ }^{20}$ Andrews, Michelle, "As Rural Hospitals Struggle, Some Opt to Close Labor and Delivery Units," Kaiser Health News, February 23, 2016.

${ }^{21}$ Kozhimannil, Katy B., Peiyin Hung, Carrie Henning-Smith, Michelle M. Casey, and Shailendra Prasad. 2018. "Association between Loss of Hospital-Based Obstetric Services and Birth Outcomes in Rural Counties in the United States," JAMA 319(12): 1239-1247. doi:10.1001/jama.2018.1830 
Regional Brief | 2019-01 | Declining Access to Health Care in Northern New England

${ }^{22}$ Searing, Adam, "More Rural Hospitals Closing in States Refusing Medicaid Coverage Expansion," Georgetown University Health Policy Institute Center for Children and Families, October 29, 2018.

${ }^{23}$ Morse, Susan, "North Country Healthcare Affiliates Four Critical Access Hospitals in New Hampshire," Healthcare Finance, December 30, 2015. As of February 2019, three of those hospitals remain in the consortium (Koziol, John, "Littleton Regional Healthcare Withdraws from Regional Partnership," New Hampshire Union Leader, February 24, 2019).

${ }^{24}$ Northern Light C.A. Dean Hospital in Greenville, Northern Light Sebasticook Valley Hospital in Pittsfield, Mayo Regional Hospital in Dover-Foxcroft, and Calais Regional Hospital are among 25 hospitals in the nation that have won the award, which entitles them to technical assistance from rural health experts (Pendharkar, Eesha, "Mayo and C.A. Dean Among Five Rural Maine Hospitals to Receive Expert Help to Run Sustainably," The Piscatiquis Observer, February 14, 2019). 